\title{
Outcome of Surgical and Radiotherapy Treatment of Medduloblastoma (Our Experience in 15 Cases)
}

\author{
Muhammad Arshad* \\ Department of Neurosurgery, Quaid-E-Azam medical college(qamc)/Bahawal Victoria Hospital (bvh), Pakistan
}

Submission: November 23, 2016; Published: January 23, 2017

*Corresponding author: Muhammad Arshad, Associate professor of neurosurgery, quaid-e-azam medical college(qamc)/bahawal Victoria hospital (bvh), Bahawalpur, Pakistan, Email: dr_arshadpk@yahoo.com

\section{Abstract}

It is a study of fifteen (15) cases of Medulloblastoma operated at The Department of Neurosurgery, Quaid-e-Azam Medical College/B.V. Hospital Bahawalpur. Study span is three years from January 2004 to December 2006 with follow up period of 5 years. Age range was 2-12 years with average age of 7 years. Eight (8) patients were male and seven(7) were female. In all patients surgery was performed. Radiotherapy (Craniospinal Axis) was given to all but two patients who expired before the initiation of radiotherapy, one patient died, two week after surgery and second patient, one months after surgery. Out of Thirteen (13) patients who were treated by surgery and radiotherapy, 4 died before 5 year of age (between 3 and 5 year of age) and 9 patients were alive at 5 year follow up. So, our 3 year survival rate was $86.66 \%$ and 5 year survival rate was $60 \%$. Chemotherapy was not given to any patient. Mortality after surgery was $13.33 \%$.

It is concluded that mainstay of treatment for medulloblastoma is surgery followed by radiotherapy to the whole craniospinal axis. In some high risk infant patients' chemotherapy is being given instead of radiotherapy, after surgery.

Keywords: Medulloblastoma; Radiotherapy; Chemotherapy; Posterior Fossa Syndrome

\section{Introduction}

Medulloblastoma is a long name made up of three smaller words: medulla= Latin for marrow, meaning inner substance or core; blastos $=$ Greek word for germ, meaning young, primitive, not fully developed; and oma = Greek for tumor. In other words, this is a tumor of primitive, undeveloped cells located inside the cerebellum [1].

Medulloblastoma is the most common malignant brain tumour in children accounting for $15-20 \%$ of primary CNS tumors and about $40 \%$ of all posterior fossa tumors. This is highly invasive embryonal neuroepithelial tumor arising in the cerebellum and have the tendency to disseminate throughout the CNS early in its course [2].

One half of primary brain tumors in children originate in the posterior fossa. Medulloblastomas are highly malignant brain tumors; they are the most common malignant posterior fossa tumors in pediatric population.They are characterized by their tendency to seed along the neuraxis, following CSF pathways, and they represent one of the few brain tumors, including ependymomas, pineablastoma and lymphoma ,to metastasize to extra neural tissues. Originally classified as a glioma, medulloblastoma is now referred to as a primitive neuroectodermal tumour (PNET) [3-7].
The exact cause(s) of medulloblastoma are not known. It does not appear to "run in families" or to be directly inherited from the parents. However, medulloblastoma is associated with certain chromosomal abnormalities that probably occur at some point during a child's development. This includes not only development after birth, but also the prenatal period before a baby is born, while it is still a growing embryo or fetus. One possible cause that has been suggested is exposure of the fetus to certain causative viruses or environmental agents, but this theory remains under investigation [1].

\section{Materials and Methods}

It is study of 15 patients of Medulloblastoma who were operated for their disease at The Department of Neurosurgery Quaid-e-Azam Medical College/Bahawal Victoria Hospital Bahawalpur. Study span is three years from January 2004 to December 2006 with follow up period of 5 years. Age range was 2 to 12 years with average age of seven (7) years. Eight (8) patients were male and seven (7) were female. In all the patients V.P. Shunt was inserted, in two patients at the time of Tumour surgery and in thirteen patients, about one week before surgery of tumor to relieve the symptoms of hydrocephalus and reduce the intracranial pressure which was a facilitating factor for the tumor surgery. All the patients but two who died within 
one month of surgery, underwent radiotherapy treatment, about four week after surgery. Craniospinal axis radiotherapy was given to all these remaining thirteen (13) patients. In all the patients the main diagnostic tool was MRI scan before and after surgery. PostOp MRI was performed, 72 hours after surgery to evaluate any residual tumour and extent of brain edema due to surgical trauma. Chemotherapy was not given to any patient. Gross total resection was achieved in eight (8)53.33\% patients and near total resection was achieved in seven (7) $46.66 \%$ patients.

\section{Results}

Two (2) patients died within one month of surgery. One female patient about 12 years of age, she did well after surgery for one week. After that she developed dysentry and melaena. We consulted pediatrician for her treatment. He took the charge of treatment but she did not come out from her illness and expired on 15 th day of surgery from her GIT problem. Second male patient of two years, developed posterior fossa syndrome after surgery and after one week of surgery he developed meningitis and he could not be saved even with our best treatment for meningitis and he died one month after surgery. (Operative Mortality was $13.33 \%$ ). Other thirteen (13) patients were subjected to radiotherapy after surgery and followed up for 5 years. Four (4) patients died before the age of 5 years (between 3 and 5 years) and only nine (9) patients could reach the age of 5 years with surgical as well as radiotherapeutic treatment of their illness. So our three (3) year survival rate after surgical and radiotherapeutic treatment was $86.66 \%$ and five (5) year survival was 60\% (Table 1).

Table 1: Survival Rate and Operative Mortality.

\begin{tabular}{|c|c|c|c|c|c|}
\hline S.NO & $\begin{array}{c}\text { No. of } \\
\text { Patients }\end{array}$ & $\begin{array}{c}\text { Alive at 3 } \\
\text { Year }\end{array}$ & $\begin{array}{c}\text { Alive at 5 } \\
\text { Year }\end{array}$ & $\begin{array}{c}\text { Operative } \\
\text { Mortality }\end{array}$ & $\begin{array}{c}\text { Percentage } \\
\%\end{array}$ \\
\hline 1 & 15 & 13 & --------- & ----------- & 86.66 \\
\hline 2 & 15 & ----------- & 09 & -------- & 60.00 \\
\hline 3 & 15 & ----------- & -------- & 02 & 13.33 \\
\hline
\end{tabular}

\section{Discussion}

Medulloblastma is the most common malignant brain tumor in children, accounting for $10-20 \%$ primary CNS neoplasms and approximately $40 \%$ off all posterior fossa tumors. With aggressive surgery, craniospinal radiotherapy and chemotherapy, more than $50 \%$ of children with medulloblastoma can be expected to be free of disease 5 year later. Using current treatments,80-90\% of those without disseminated disease can be cured; however treatment for this disease often results in endocrinological and intellectual sequelae [2].

The treatment advised for medulloblastoma is surgical exploration with removal of as much of the tumor as possible without increasing unduly the operative risk.This must be followed by irradiation of the entire cerebrospinal axis.The survival rate is greater for patients in whom a complete surgical excision of the tumor was performed,compared with lesser procedures.While grave prognosis associated with medulloblastoma is fully justified,it appears that some hope can be given to parents of children with this disease,since practically $40 \%$ of our patients completing treatment have survived 5 years,and 30\%, 10 years [8].

In a study done by Leon Herisiadis, et al. [9] (59) fifty nine children with cerebellar medulloblastoma were followed prospectively after they were staged and treated consistently with post operative megavoltage radiotherapy to the entire neural axis. The probabilities of surviving 5 and 10 years were $40.4 \%$ and $30.9 \%$ respectively. John Mealey JR, et al. [10] reviewed treatments and results in 45 cases of medulloblastoma arising in children. The surgical mortality rate observed was $11 \%$. of those completing postoperative cerebrospinal irradiation at this institution, $53 \%$ have survived for 3 years, $41 \%$ for 5 years, and $22 \%$ for ten years. The extent of surgical resection of the cerebellar tumor had no significant bearing on prognosis according to their study.

Certain studies have shown a correlation between improved posterior fossa control and shorter periods for the completion of radiotherapy [8]. In chan et al. series the 5 year posterior fossa control rate was $81 \%$ in patients who completed radiotherapy in less than 48 days, compared with $51 \%$ for patients who completed radiotherapy in 48 days or more.Recently, adjuvant chemotherapy also has been shown to be beneficial in children with medulloblastoma [7,11]. A series of 80 cases of medulloblastomas in childern undergoing operation and postoperatively followed between 1980-1990 at Great Ormond Street Hospital for Childern has been reviewed and compared to an earlier series reported from the same institution by Mcintosh. The overall 5 year survival rate for the present series was $50 \%$, although 3 patients died after surviving 5 years. The operative mortality rate was $5 \%$. Those patients with no spinal metastasis and total tumor removal had a 5 year survival rate of $73 \%$, making this the most favorable group in the series $[12,13]$.

In a study made by Jenkin $\mathrm{D}$ et al. for posterior fossa medulloblastoma in childhood for treatment results and a proposal for a new staging system, the five (5) year survival and disease-free survival rates were $71 \%$ and $64 \%$.It is close to survival rate $(60 \%)$ in our study.Total tumor resection, as determined by the surgeon was the most significant favorable prognostic factor [13].

A retrospective review was done by Awasthy BS, et al. in 45 patients at the All India Institute of Medical Sciences to asses the outcome and prognostic factors for these patients who received post operative radiotherapy with or without chemotherapy for medulloblastoma. The medium age at diagnosis was 11 years. Complete macroscopic removal was achieved in 24 (53.33\%) patients and subtotal removal in $21(46.66 \%)$ patients and same was the percentage of total and subtotal removal of tumor in our cases. $41(91.11 \%)$ patients underwent craniospinal irradiation. In our series $13(86.66 \%)$ patient were subjected to irradiation treatment after surgery because two patients were died before the initiation of radiotherapy. Median overall and disease free survival 
was 57 and 31 months and 3 year overall survival was 76\% [14]. Our overall 5 year survival rate was $60 \%$ after combined surgical and radiotherapeutic treatment. Extent of surgery was a significant factor for overall survival.

51 Paediatric patients with a median age of 7 years, the same median age as in our study, were treated in the National Cancer Institute-Cairo University. Patients were treated by surgery and craniospinal radiotherapy. For the pediatric patients the 5 year overall survival rate was $89 \%$ [15], while overall survival rate in our study was $60 \%$ [16-19].

\section{Conclusion}

Medulloblastoma is the most common malignant brain tumour in children accounting for $15-20 \%$ of primary CNS tumors and about $40 \%$ of all posterior fossa tumors. This is highly invasive embryonal neuroepithelial tumor arising in the cerebellum and have the tendency to disseminate throughout the CNS early in its course.

The mainstay of treatment for medulloblastoma is surgery followed by radiotherapy to the whole craniospinal axis. In some high risk infant patients' chemotherapy is being given instead of radiotherapy after surgery.

With aggressive surgery, craniospinal radiotherapy and chemotherapy, more than $50 \%$ of children with medulloblastoma can be expected to be free of disease 5 year later. Using current treatments, $80-90 \%$ of those without disseminated disease can be cured.

\section{References}

1. Neha Vapiwala, John P Updated by J Taylor Whaley (2011) Medulloblastoma: Overview.

2. Tobey MacDonald, Roger J Packer, Kathleen M Sakamoto, Mary L Windle, Steven K Bergstorm, et al. (2012) Pediatric Medulloblastoma. Medscape Reference, Drug Diseases and Procedures.

3. Bloom HJ,Glees J,Bell J, Ashley SE, Gorman C, et al. (1990) The Treatment and long term prognosis of children with intracranial tumors: a study of 610 cases.1950-1981. Intl J radiate Oncol Biol Phys. 8(4): 723-745.

4. Rutka JT (1997) Medulloblastoma. Clin Neurosurg 44: 571-585.

5. Zee CS, Segall HD, Nelson M (1993) Infratentorial Tumours in Childern. Neuroimaging Clinics of North Am 3(4): 705-714.
6. Yazigi-Rivard L, Masserot C, Lachenaud J, Diebold-Pressac I, Aprahamian A, et al. (2008) [Childhood medulloblastoma]. Arch Pediatr 15(12): 1794-1804.

7. Menon G, Nair S, Muthurethinam T, Krishnakumar K, battacharya RN (2006) Medulloblastoma in Childern:Prognostic Factors and Predictors of out come. J Pediatr Neurosci 1(1): 16-20.

8. Bloom HJ, Wallace EN, Henk JM (1969) The Treatment and Prognosis of Medulloblastoma in Childern. A Study of 82 Varified Cases. Am J Roentgenol Radium Ther Nucl Med 105(1): 43-62.

9. Harisiadis L, Chang CH (1977) Medulloblastoma in Childern: A correlation between staging and results of treatment. Intl J of Rad Oncl Biol Phys 2(9): 833-841.

10. John Mealey, Jr MD, Peter V Hall (1977) Medulloblastoma in Childern, Survival and Treatment. Journal of Neurosurgery 46(1): 56-64.

11. Park TS, Hoffman HJ, Hedrick EB, Humphreys RP, Becker LE (1983) Medulloblastoma: Clinical Presentation and Management. Experience at the hospital for sick children, toronto, 1950-1980. J Neurosurg 58(4): 543-552.

12. David KM, Casey AT, Hayward RD, Harkness WF, Phipps K, et al. (1997) Medulloblastoma;is the- 5 year survival rate improving ? A review of 80 cases from a single institution. J Neurosurg 86(1): 13-21.

13. Jenkin D,Goddard K,Armstrong D,Becker L,Berry M, et al. (1990) Posterior Fossa Medulloblastoma In Childhood:Treatment results and a Proposal for a new staging system. Int J Radiate Oncol Biol Phys 19(2): 265-274.

14. Awasthy BS, Das Gupta C, Patel AK, Julka Pk (1997) MedulloblastomaA Retrospective Analysis. Indian J Pediatr 64(5): 693-697.

15. Khalil EM (2008) Treatment results of adults and children with Medulloblastoma NCI, Cairo University experience.J Egypt Natl Canc Inst 20(2):175-186.

16. Djamil Fertikh, Michael L Brooks, Chi-Shing Zee, Bernard D Coombs, Douglas Phillips, et al. Medullobl;astoma Imaging. Medscape References, Drug Diseases \& Procedures.

17. Packer RJ, Vezina G (2008) Management of and Prognosis with Medulloblastoma: Therapy at a Crossroads. Arch Neurol 65(11): 14191424.

18. Thapar K, Laws ED (1995) Tumours of central nervous system. In: Clinical Oncology. Am Cancer So, pp. 396-397.

19. Prados MD, Wara W, Edwards MS, Aterr J, Rabbit J, et al. (1996) Treatment of high risk medulloblastoma and other primitive neuroectodermal tumors with reduced dose craniospinal radiothtion therapy and multi agent nitrouria based chemotherapy. Pediatr Neurosurg 25(4):174-181.

\section{Your next submission with Juniper Publishers} will reach you the below assets

- Quality Editorial service

- Swift Peer Review

- Reprints availability

- E-prints Service

- Manuscript Podcast for convenient understanding

- Global attainment for your research

- Manuscript accessibility in different formats

( Pdf, E-pub, Full Text, Audio)

- Unceasing customer service

Track the below URL for one-step submission https://juniperpublishers.com/online-submission.php 